\title{
ANALISIS PERCOBAAN FAKTORIAL UNTUK MELIHAT PENGARUH PENGGUNAAN ALAT PERAGA BLOK ALJABAR TERHADAP PRESTASI BELAJAR ALJABAR SISWA
}

\author{
Ni Putu Ayu Mirah Mariati ${ }^{1}$, Ni Luh Putu Suciptawatí ${ }^{2}$, \\ KARTIKA SARI ${ }^{3}$ \\ ${ }^{1,2,3}$ Jurusan Matematika FMIPA Universitas Udayana, Bukit Jimbaran-Bali, \\ e-mail: ${ }^{1}$ ayumirahmariati@yahoo.com, ${ }^{2}$ putusuciptawati@yahoo.co.id, \\ ${ }^{3}$ sari_kaartika@yahoo.co.id
}

\begin{abstract}
The experimental design was applied in research in many different fields of science, such as in education, as used in this study. Block algebra visual aids is a visual aids in the form of the geometry model used to concretize understanding the variables and constants in the algebra which is an abstract concept. This visual aids are used as a basis for factoring algebraic forms. In connection with this, the aims of this research is to determine the effect of the application of algebra block in student academic achievement in class VII in the field of algebra in schools categorized as private, SSN (Sekolah Standar Nasional) and the previously categorized RSBI (Rintisan Sekolah Bertaraf Internasional). The method of analysis used in this study was two-factor experimental design in a randomized block design. The results showed that the academic achievement of students in the field of algebra after learning with block algebra visual aids obtained better than the academic achievement of students who received learning without using block algebra visual aids. Moreover, it also shows that the categories of schools have a significant effect on student achievement.
\end{abstract}

Keywords: analysis of variance, experiments design, block algebra visual aids

\section{Pendahuluan}

Model analisis ragam merupakan suatu jenis dasar model statistik yang pada dasarnya digunakan untuk menganalisis pengaruh peubah bebas terhadap peubah tak bebas [4]. Jika $y$ merupakan peubah tak bebas yang bersifat kontinu dan $x$ peubah bebas yang bersifat kategori maka analisis ragam dapat digunakan. Secara garis besar rancangan percobaan yang menggunakan analisis ragam dapat diklasifikasikan sebagai berikut: rancangan perlakuan yang terdiri dari satu faktor, dua faktor dan tiga faktor atau lebih, selanjutnya rancangan lingkungan yang terdiri dari rancangan acak lengkap, rancangan acak kelompok, rancangan bujur sangkar latin dan rancangan Lattice [3]. Rancangan percobaan dalam penelitian ini adalah percobaan dua faktor khususnya dalam rancangan acak kelompok yang diterapkan dalam kasus pendidikan. Pendidikan sangat penting dalam menentukan kualitas sumber daya manusia. Salah satu indikator yang dapat digunakan untuk

${ }^{1}$ Mahasiswa Jurusan Matematika FMIPA Universitas Udayana

${ }^{2,3}$ Staf Pengajar Jurusan Matematika FMIPA Universitas Udayana 
melihat kualitas pendidikan adalah prestasi belajar siswa. Secara umum, prestasi belajar siswa di bidang matematika termasuk aljabar tergolong sangat rendah[5]. Hal ini terjadi karena beberapa hal, antara lain penerapan metode pembelajaran yang kurang tepat. Sehubungan dengan pembelajaran aljabar, terdapat suatu metode pembelajaran dengan menggunakan alat peraga blok aljabar. Melalui penggunaan alat peraga tersebut, hal-hal yang abstrak dapat disajikan dalam bentuk model yang berupa benda konkret yang dapat dilihat, dipegang, diputarbalikkan sehingga dapat lebih mudah dipahami [6].

Berikut ini diberikan contoh penggunaan alat peraga blok aljabar untuk memfaktorkan bentuk aljabar. Perhatikan alat peraga berikut ini:

Alat peraga blok yang menunjukkan faktorisasi dari $-x^{2}+3 x-2$ adalah

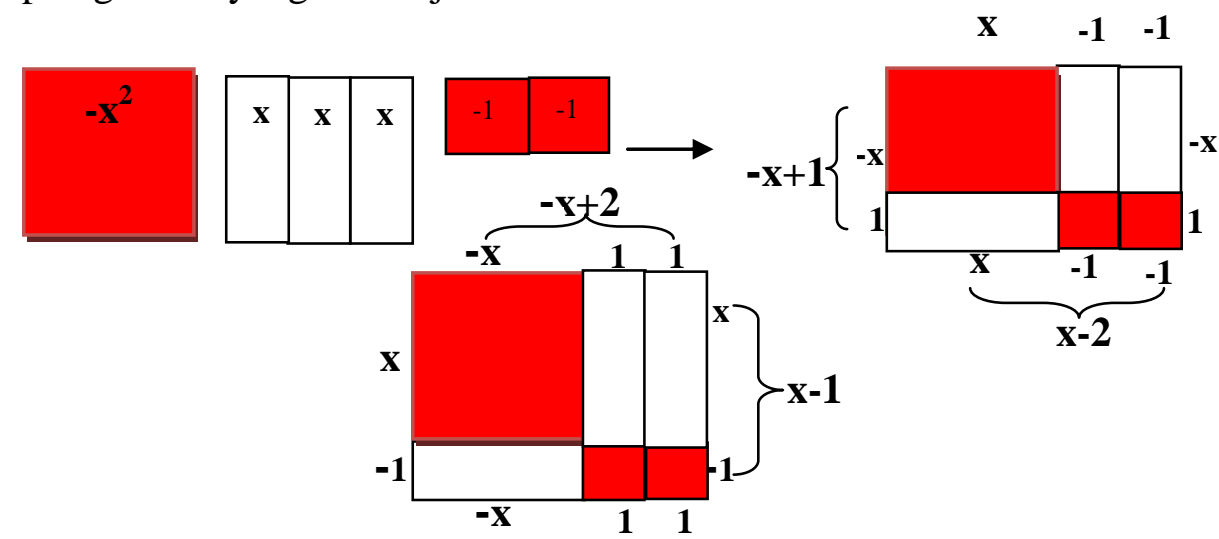

Dengan menggunakan konsep menghitung luas persegi panjang diperoleh bahwa faktorisasi dari $-x^{2}+3 x-2$ adalah $(-x+1)(x-2)$ atau $(x-1)(-x+2)$.

Untuk mengetahui efektivitas pembelajaran dengan menggunakan alat peraga blok aljabar, dilakukan penelitian membandingkan prestasi belajar siswa hasil pembelajaran dengan menggunakan alat peraga blok aljabar dan tanpa menggunakan alat peraga blok aljabar. Penelitian ini dilakukan pada tiga kategori sekolah, yaitu swasta, Sekolah Standar Nasional (SSN) dan sekolah yang sebelumnya berkategori Rintisan Sekolah Bertaraf Internasional (RSBI).

\section{Metode Penelitian}

Penelitian ini diawali dengan pre-test dan diakhiri dengan post-test. Dari nilai pre-test setiap kelas dikelompokkan dalam 3 kelompok, yaitu kelompok siswa dengan kategori nilai tinggi, sedang dan rendah. Dari kelompok siswa tersebut juga diperoleh rata-rata post-test dalam kelompok tinggi, sedang dan rendah. Selanjutnya, dari rata-rata nilai post-test kemudian dianalisis menggunakan Percobaan Dua Faktor dalam Rancangan Acak Kelompok yang disingkat dengan RAK Faktorial. Untuk tabulasi data hasil percobaan menurut kelompok dan kombinasi pada Percobaan Dua Faktor dalam Rancangan Acak Kelompok dapat dilihat pada Tabel 1[2]. 
Tabel 1. Tabulasi Data Menurut Kelompok dan Kombinasi Perlakuan

\begin{tabular}{|c|c|c|c|c|c|}
\hline \multirow{3}{*}{ Faktor A } & \multirow{3}{*}{ Kelompok } & \multicolumn{3}{|c|}{ Faktor B } & Total \\
\cline { 2 - 6 } & 1 & $\mathrm{~B}_{0}$ & $\mathrm{~B}_{1}$ & $\mathrm{~B}_{2}$ & $\left(\mathrm{Y}_{\mathrm{i} . .}\right)$ \\
\hline \multirow{4}{*}{$\mathrm{A}_{1}$} & 2 & $\mathrm{Y}_{111}$ & $\mathrm{Y}_{121}$ & $\mathrm{Y}_{131}$ & \\
\cline { 2 - 6 } & 3 & $\mathrm{Y}_{112}$ & $\mathrm{Y}_{122}$ & $\mathrm{Y}_{132}$ & \\
\cline { 2 - 6 } & Total $\left(\mathrm{Y}_{1 \mathrm{j}}\right)$ & $\mathrm{Y}_{113}$ & $\mathrm{Y}_{123}$ & $\mathrm{Y}_{133}$ & \\
\cline { 2 - 6 } & 1 & $\mathrm{Y}_{11 .}$ & $\mathrm{Y}_{12 .}$ & $\mathrm{Y}_{13 .}$ & $\mathrm{Y}_{1 . .}$ \\
\cline { 2 - 6 } & 2 & $\mathrm{Y}_{211}$ & $\mathrm{Y}_{221}$ & $\mathrm{Y}_{231}$ & \\
\cline { 2 - 6 } $\mathrm{A}_{2}$ & 3 & $\mathrm{Y}_{212}$ & $\mathrm{Y}_{222}$ & $\mathrm{Y}_{232}$ & \\
\cline { 2 - 6 } & Total $\left(\mathrm{Y}_{2 \mathrm{j}}\right)$ & $\mathrm{Y}_{213}$ & $\mathrm{Y}_{223}$ & $\mathrm{Y}_{233}$ & \\
\hline Total & & $\mathrm{Y}_{21 .}$ & $\mathrm{Y}_{22 .}$ & $\mathrm{Y}_{23 .}$ & $\mathrm{Y}_{2 . .}$ \\
\hline
\end{tabular}

\section{Hasil dan Pembahasan}

Berdasarkan nilai rata-rata post-test pada masing-masing kategori diperoleh hasil seperti pada Tabel 2 berikut ini.

Tabel 2.Tabulasi Data Menurut Kelompok, Faktor Metode dan Kategori Sekolah

\begin{tabular}{|c|c|c|c|c|c|}
\hline \multirow[b]{2}{*}{ Metode Pembelajaran (A) } & \multirow[b]{2}{*}{ Kelompok (r) } & \multicolumn{3}{|c|}{ Kategori Sekolah (B) } & \multirow[b]{2}{*}{ Total } \\
\hline & & RSBI & SSN & Swasta & \\
\hline \multirow{4}{*}{$\begin{array}{c}\text { Menggunakan Alat Peraga } \\
\text { Blok Aljabar }\end{array}$} & Tinggi & 91,54 & 90,77 & 75,71 & 258,02 \\
\hline & Sedang & 90 & 78,82 & 72,14 & 240,96 \\
\hline & Rendah & 78,75 & 78,33 & 60,83 & 217,91 \\
\hline & & 260,29 & 247,92 & 208,68 & 716,89 \\
\hline \multirow{3}{*}{$\begin{array}{l}\text { Tanpa Menggunakan Alat Peraga } \\
\text { Blok Aljabar }\end{array}$} & Tinggi & 85 & 82,73 & 62,5 & 230,23 \\
\hline & Sedang & 81,54 & 75 & 61,67 & 218,21 \\
\hline & Rendah & 52,22 & 48 & 46,36 & 146,58 \\
\hline \multirow[t]{2}{*}{ Total } & & 218,76 & 205,73 & 170,53 & 595,02 \\
\hline & & 479,05 & 453,65 & 379,21 & $1.311,91$ \\
\hline
\end{tabular}

Sebelum melakukan pengujian analisis ragam, berikut ini akan dilakukan pengujian asumsi analisis ragam:

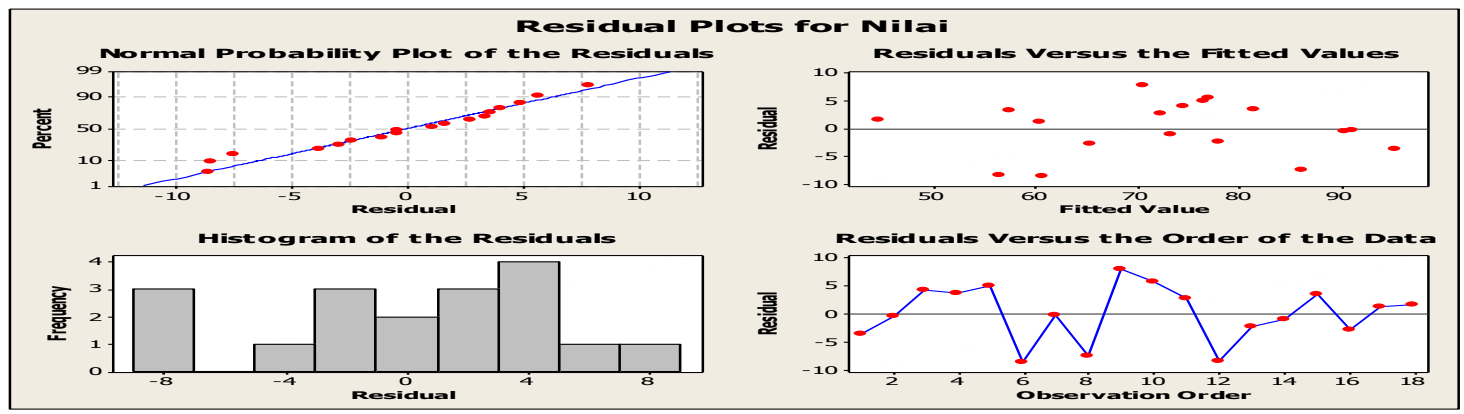

Gambar 1. Output Pengujian Asumsi

Pada Gambar 1 diintepretasikan bahwa berdasarkan hasil plot residuals versus the order of the data yang berbentuk acak menunjukkan bahwa residual bersifat bebas, sedangkan hasil plot residuals versus the fitted values yang tidak menunjukkan pola tertentu mengindikasikan bahwa ragam residual bersifat 
homogen dan hasil plot normal probability plot of the residuals yang membentuk pola garis lurus menunjukkan bahwa residual menyebar normal. Dengan demikian asumsi-asumsi pada analisis ragam telah terpenuhi. Langkah selanjutnya adalah melakukan analisis dengan menggunakan RAK Faktorial dan hasilnya adalah sebagai berikut.

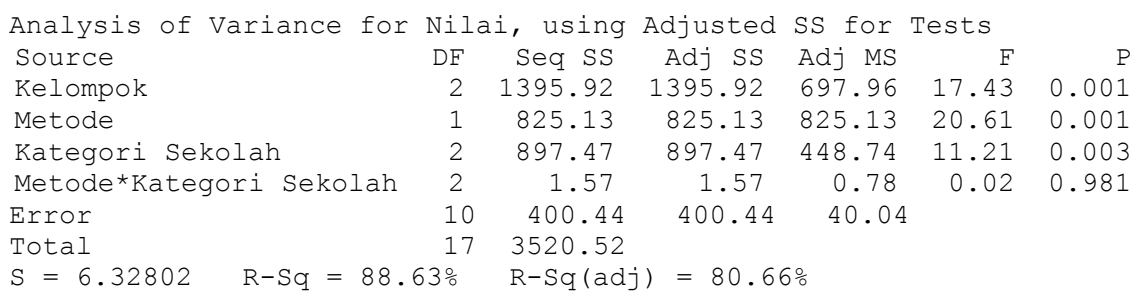

Dari output terlihat bahwa faktor kelompok, metode dan kategori sekolah mempunyai pengaruh yang signifikan terhadap prestasi belajar siswa di bidang aljabar. Selanjutnya, dengan $\alpha=0,05$ tampak bahwa prestasi belajar siswa yang diperoleh melalui pembelajaran dengan alat peraga blok aljabar berbeda dengan prestasi belajar siswa yang diperoleh melalui pembelajaran tanpa menggunakan alat peraga blok aljabar. Rata-rata prestasi siswa yang diberi pembelajaran dengan menggunakan alat peraga blok aljabar adalah 79,65 sedangkan rata-rata prestasi siswa yang diberi pembelajaran tanpa menggunakan alat peraga blok aljabar adalah 66,11. Dapat disimpulkan bahwa prestasi belajar siswa hasil pembelajaran dengan menggunakan alat peraga blok aljabar lebih baik daripada prestasi belajar siswa tanpa menggunakan alat peraga blok aljabar.

Sebagai langkah berikutnya dilakukan analisis lanjutan (perbandingan nilai tengah perlakuan) yang dilakukan apabila perlakuan yang digunakan lebih dari dua $^{[1]}$. Metode yang dapat digunakan untuk membandingkan nilai tengah perlakuan adalah beda nyata terkecil (BNT) untuk faktor kategori sekolah.

\section{Uji Beda Nyata Terkecil (BNT)}

Adapun hipotesis dari perbandingan dengan metode BNT adalah sebagai berikut: $\mathrm{H}_{0}: \mu_{i}=\mu_{i}{ }^{\prime}$ dan $\mathrm{H}_{1}: \mu_{i} \neq \mu_{i}{ }^{\prime}$

Berdasarkan hasil analisis data, Faktor Kategori Sekolah berpengaruh nyata sehingga selanjutnya adalah menghitung uji BNT pengaruh utama kategori sekolah yang akan dibahas berikut ini.

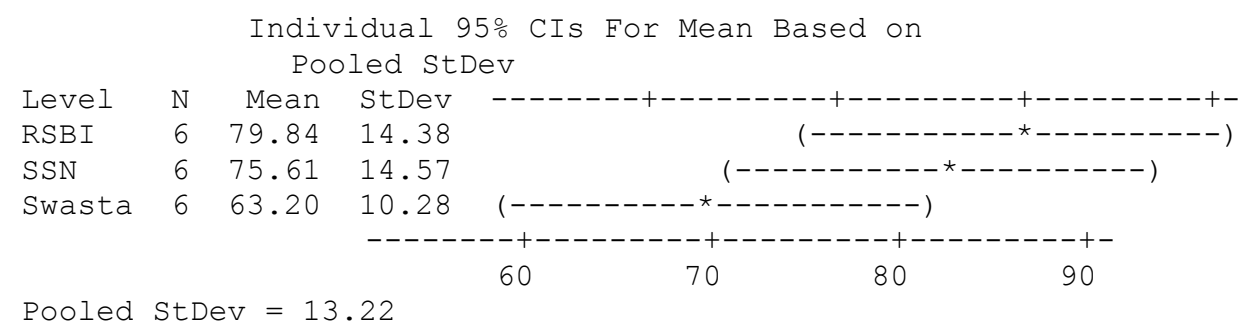


Berdasarkan output di atas siswa yang bersekolah di sekolah yang sebelumnya berkategori RSBI dengan sekolah yang berkategori SSN tidak memiliki perbedaan kemampuan yang signifikan sedangkan sekolah berkategori SSN dan yang sebelumnya berkategori RSBI memiliki perbedaan kemampuan dengan sekolah yang berkategori swasta.

\section{Kesimpulan}

Berdasarkan hasil penelitian yang dilakukan pada ketiga kategori sekolah diperoleh kesimpulan sebagai berikut:

1. Prestasi belajar siswa di bidang aljabar yang diperoleh setelah diberikan pembelajaran dengan alat peraga blok aljabar lebih baik, dibandingkan prestasi belajar siswa yang diberikan pembelajaran tanpa alat peraga blok aljabar.

2. Kategori sekolah memiliki pengaruh yang signifikan terhadap prestasi belajar siswa di bidang aljabar.

\section{Daftar Pustaka}

[1] Hanafiah, Kemas Ali. 2003. Rancangan Percobaan Teori \& Aplikasi. Jakarta:PT Raja Grafindo Persada.

[2] Mattjik, Ahmad Ansori dan Sumertajaya, I Made. 2000. Perancangan Percobaan dengan Aplikasi SAS dan Minitab. Edisi kesatu:IPB PRESS Bogor.

[3] Montgomery Douglas C. 1991. Design and Analysis of Experiment, Third Edition. John Wiley \& Sons.

[4] Neter, J., W. Wasserman, dan M.H Kutner. 1997. Model Linear Terapan, Buku III: Analisis Ragam. Diterjemahkan oleh: Bambang Sumantri.

[5] Sadiman, Arief., dkk. 2009. Media Pendidikan Pengertian, Pengembangan, dan Pemanfaatannya. Jakarta: Rajawali Pers.

[6] Sobel, Max A. dan Maletsky, Evan M. 2004. Mengajar Matematika. Jakarta: Penerbit Erlangga. 